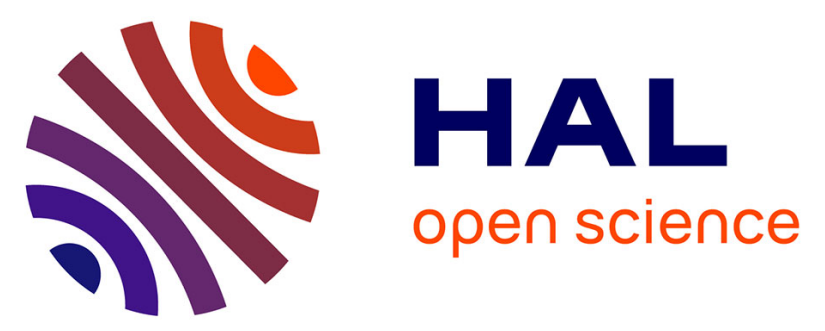

\title{
Radiochemical stability of dicyclohexano-18-crown-6 ether (DCH18C6) and its use in a recovery process of strontium from acidic nuclear waste stream
}

\author{
M. Draye, A. Favre Reguillon, J. Foos, A. Guy, M. Lemaire
}

\section{To cite this version:}

M. Draye, A. Favre Reguillon, J. Foos, A. Guy, M. Lemaire. Radiochemical stability of dicyclohexano18-crown-6 ether (DCH18C6) and its use in a recovery process of strontium from acidic nuclear waste

stream. Radiochimica Acta, 1997, 78, pp.105-109. 10.1524/ract.1997.78.special-issue.105 . hal00006669

\section{HAL Id: hal-00006669 \\ https://hal.science/hal-00006669}

Submitted on 1 Oct 2021

HAL is a multi-disciplinary open access archive for the deposit and dissemination of scientific research documents, whether they are published or not. The documents may come from teaching and research institutions in France or abroad, or from public or private research centers.
L'archive ouverte pluridisciplinaire HAL, est destinée au dépôt et à la diffusion de documents scientifiques de niveau recherche, publiés ou non, émanant des établissements d'enseignement et de recherche français ou étrangers, des laboratoires publics ou privés. 


\title{
Radiochemical Stability of Dicyclohexano-18-Crown-6 Ether (DCH18C6) and its Use in a Recovery Process of Strontium from Acidic Nuclear Waste Stream*
}

\author{
By M. Draye, A. Favre-Réguillon, J. Foos, A. Guy \\ Laboratoire des Sciences Nucléaires du CNAM, 2 rue Conté, 75003 Paris, France
}

and M. Lemaire

Institut de Recherches sur la Catalyse, Laboratoire de Catalyse et Synthèse Organique, UCBL, CPE, 43, boulevard du 11 Novembre 1918, 69622 Villeurbanne Cédex, France

\section{DCH18C6 stability / Radiostrontium / Ion exchanger / Radwaste}

\begin{abstract}
Summary
The cis-syn-cis isomer of the dicyclohexano-18-crown- 6 ether (DCH18C6) was subjected to radiolysis with a ${ }^{137} \mathrm{Cs} \gamma$-source. The cis-syn-cis DCH18C6 radiolytic products were synthesized in their different configurations and tested on aqueous synthetic solutions of spent nuclear fuels: no influence of the degradation products was detected. So, good prospects for the application of DCH18C6 to the spent nuclear fuels reprocessing as well as liquid effluents treatment was demonstrated. Thus, a process combining selective liquid-liquid extraction ( $\mathrm{DCH} 18 \mathrm{C} 8-\mathrm{CHCl}_{3}$ ) with solid-liquid extraction (Duolite ARC-9652) for strontium traces removal from acidic waste streams is described. This process allows to a high strontium decontamination factor (250) with a very important extraction factor [1] (5000) in the presence of $30 \cdot 10^{3}$ molar excess of sodium.
\end{abstract}

\section{Introduction}

Tributyl phosphate (TBP), which is used in solvent extraction for decades in a considerable number of industrial applications such as the PUREX process in spent nuclear fuel reprocessing, has now reached a maximum in efficiency, selectivity and safety. Indeed, the main drawback of this extractant is its susceptibility to both chemical and radiolytic degradation, and a consequence of this defect is that the operation of nuclear fuel reprocessing plants is affected.

Research of new more effective extractants has given rise to many works that show the importance of crown ethers in separation chemistry of metal ions [15] and, in particular, of dicyclohexano-18-crown-6 (DCH18C6) 1 [6-7].

During the last several decades, considerable effort has been directed toward the development of improved processes for the removal and recovery of strontium90 from nuclear waste streams. This radionuclide,

* Presented at the 4th International Conference on Nuclear and Radiochemistry, St. Malo, France, September 1996. along with cesium-137, constitutes a major source of heat in these wastes. Its removal would therefore greatly simplify their handling and ultimate disposal. These last years, solvent extraction [8] and ion exchange processes [9] for $\mathrm{Sr}$ isolation from alkaline, weak or strong acid waste solutions have been developed, however, none of the processes described to date has proven satisfactory [10].

The present work is aimed at studying the effect of $\gamma$-radiations on the structure and on the physicochemical properties of the DCH18C6, and to describe a continuous process combining liquid-liquid extraction with ion exchange techniques for strontium traces removal from aqueous solutions, in the presence of high sodium concentrations.

\section{Experimental}

\section{Materials}

All reagents were purchased commercially and used as-received. The DCH18C6 isomers were separated according to a procedure previously described [11]. The Duolite ${ }^{\mathrm{TM}}$ ARC-9652 resin contained $1.2 \mathrm{meq}$ of strong acid exchange sites $\left(\mathrm{SO}_{3} \mathrm{H}\right)$ per $\mathrm{g}$ of resin. All syntheses of DCH18C6 degradation products were performed according to the procedures previously described [12]. The influence of DCH18C6 radiolytic products on $\mathrm{Pu}, \mathrm{U}$ and $\mathrm{Sr}$ extraction by DCH18C6 was studied with synthetic second cycle solutions of the PUREX process. Table 1 shows the main constituents of a synthetic second-cycle solution in which $\mathrm{Pu}$ and $\mathrm{U}$ are present in macroquantities.

Recovery of strontium was carried out with simulated aqueous wastes. The simulated aqueous wastes were prepared by dissolving salts of sodium and strontium nitrates in nitric acid. The composition of the synthetic waste used in this study is shown in Table 2. 
Table 1. Composition of the synthetic second-cycle solution

\begin{tabular}{|c|c|c|c|c|c|c|}
\hline Nuclide & $\mathrm{Pu}$ & ${ }^{90} \mathrm{Sr}$ & ${ }^{241} \mathrm{Am}$ & ${ }^{60} \mathrm{Co}$ & ${ }^{106} \mathrm{Ru}$ & ${ }^{106} \mathrm{Rh}$ \\
\hline Activity, $\mathrm{Bq} \mathrm{L}^{-1}$ & $2.29 \cdot 10^{9}$ & $24.79 \cdot 10^{6}$ & $38.11 \cdot 10^{6}$ & $14.8 \cdot 10^{3}$ & $7.77 \cdot 10^{6}$ & $7.77 \cdot 10^{6}$ \\
\hline Concentration, $\mathrm{g} \mathrm{L}^{-1}$ & 1 & $4.75 \cdot 10^{-6}$ & $300 \cdot 10^{-6}$ & $354 \cdot 10^{-12}$ & $63 \cdot 10^{-9}$ & $6 \cdot 10^{-14}$ \\
\hline Nuclide & U & ${ }^{134} \mathrm{Cs}$ & ${ }^{137} \mathrm{Cs}$ & ${ }^{144} \mathrm{Ce}$ & ${ }^{144} \mathrm{Pr}$ & ${ }^{154} \mathrm{Eu}$ \\
\hline Activity, $\mathrm{Bq} \mathrm{L}^{-1}$ & $13.93 \cdot 10^{3}$ & $1.18 \cdot 10^{6}$ & $20.35 \cdot 10^{6}$ & $7.4 \cdot 10^{6}$ & $7.4 \cdot 10^{6}$ & $1.85 \cdot 10^{3}$ \\
\hline Concentration, $\mathrm{g} \mathrm{L}^{-1}$ & 1.12 & $25 \cdot 10^{-9}$ & $6 \cdot 10^{-6}$ & $63 \cdot 10^{-9}$ & $2.7 \cdot 10^{-14}$ & $1.9 \cdot 10^{-16}$ \\
\hline
\end{tabular}

Table 2. Chemical composition of the synthetic effluents

$\begin{array}{ccccc}\text { Ion } & \mathrm{H}^{+} & \mathrm{NO}_{3}^{-} & \mathrm{Na}^{+} & \mathrm{Sr}^{2+} \\ \begin{array}{c}\text { Concentration } \\ \left(\mathrm{mol} \mathrm{L}^{-1}\right)\end{array} & 0.9 & 1 & 0.1 & 2.68 \cdot 10^{-6}\end{array}$

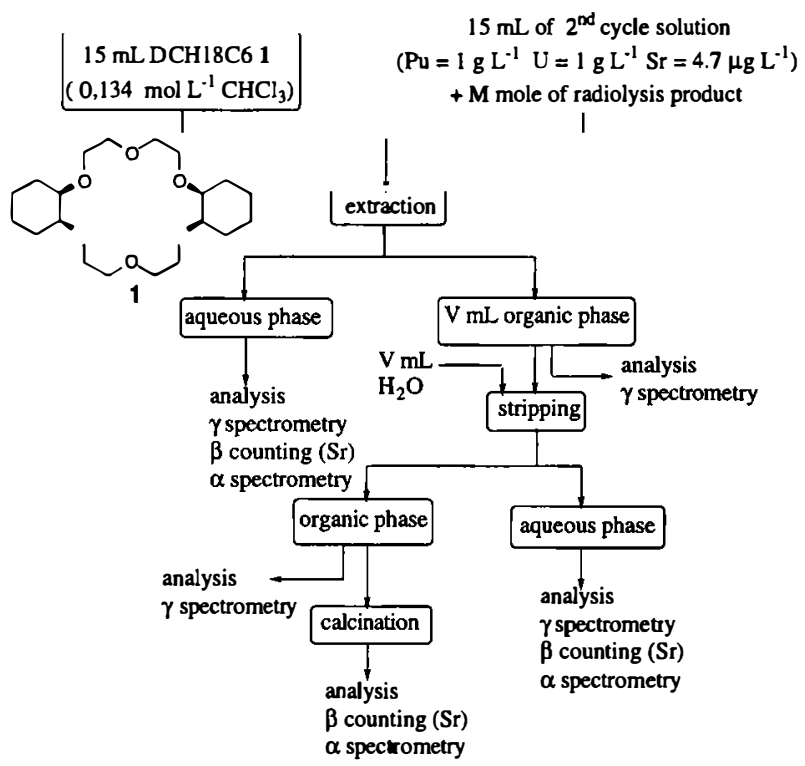

Fig. 1. Procedure of radionuclides extraction by DCH18C6 in the presence of its radiolytic products.

Effect of the radiolytic products on the extraction of $\mathrm{Pu}, \mathrm{U}$ and $\mathrm{Sr}$ by $\mathrm{DCH} 18 \mathrm{C6}$

For determination of the influence of radiolytic products of DCH18C6 in the aqueous phase on spent nuclear fuel reprocessing, $15 \mathrm{~mL}$ of second-cycle solution containing (or not) radiolytic products (7.35 . $10^{-3} \mathrm{~mol} \mathrm{~L}^{-1}$ ) were shaken with $15 \mathrm{~mL}$ of a chloroformic DCH18C6 solution $\left(0.13 \mathrm{~mol} \mathrm{~L}^{-1}\right)$. The organic solution ( $\mathrm{V} \mathrm{mL}$ ) was washed with water $(\mathrm{V} \mathrm{mL})$, chloroform was evaporated, then the organic residue was calcinated and dissolved in nitric acid (68\%). Extraction were carried out according to the procedure shown in Figure 1.

For determination of the influence of radiolytic products in the aqueous phase on Pu valence and concentration, $9.8 \cdot 10^{-3} \mathrm{~mol}$ of the radiolytic product 2 was shaken with $20 \mathrm{~mL}$ of second-cycle solution. Five samples were taken as a function of the time, to be analysed.

The concentrations of radioelements in the synthetic second-cycle solutions were measured by $\beta$ counting ( $\pm 6 \%$ of precision), $\alpha$ counting and spectrometry ( $\pm 5-10 \%$ of precision).

The $\mathrm{U}$ and $\mathrm{Pu}$ oxidation states were checked using visible absorption spectrometry. No modification of the oxidation states of the metallic species $\left(\mathrm{U}^{\mathrm{VI}}\right.$ and $\mathrm{Pu}^{\mathrm{IV}}$ ) was noticed during the extraction processes.

\section{Recovery of strontium from simulated aqueous wastes}

The pilot installation was tested with $30 \mathrm{~L}$ of radioactive effluent $\left(\mathrm{Na}^{+} 0.1 \mathrm{~mol} \mathrm{~L}{ }^{-1}, \mathrm{Sr}^{2+} 2.68 \cdot 10^{-6}\right.$ mol L ${ }^{-1}$ and $\mathrm{HNO}_{3} 0.9 \mathrm{~mol} \mathrm{~L}^{-1}$ ). Concentrations of $\mathrm{Sr}$ and $\mathrm{Na}$ were measured both radiometrically $( \pm 5 \%$ of precision) and by atomic absorption spectrometry ( $\pm 5 \%$ of precision). A mixture of ${ }^{85} \mathrm{Sr}$ and ${ }^{22} \mathrm{Na}$ isotopes was used as tracers. The tracer solutions were of sufficient activity to allow a small volume of tracer to be added which did not significantly increase the total volume of the aqueous solution.

\section{Results and discussion}

Cis-syn-cis DCH18C6 1

radiochemical stability

The DCH18C6 radiolytic products have been identified in a previous study [13]. We have noted that no product exhibits a macrocyclic structure, and the dramatically lower complexing and extracting properties of open chain polyether compared to macrocyclic "analogs" has been reported [14]. The stereochemical configuration of the cis-syn-cis DCH18C6 radiolytic products was then determined [12]. As a general rule, $\gamma$-radiations give rise to degradation products with retention of configuration, i.e. cis configuration (Fig. 2). The values of the radiochemical yields, $G$, are given Figure 2. The radiolytic products yields range from about 0.01 to nearly 0.3 molecule per $100 \mathrm{eV}$ absorbed by the DCH18C6 at an energy of $3290 \mathrm{kGy}$. As compared, at an energy of $1930 \mathrm{kGy}$, the $\mathrm{G}$ values of HDBP and $\mathrm{H}_{2} \mathrm{MBP}$, which are the main radiolytic products of TBP, are respectively $\mathrm{G}_{\mathrm{HDBP}}=2.52$ and $\mathrm{G}_{\mathrm{H}_{2} \mathrm{MBP}}=0.30[15]$. 

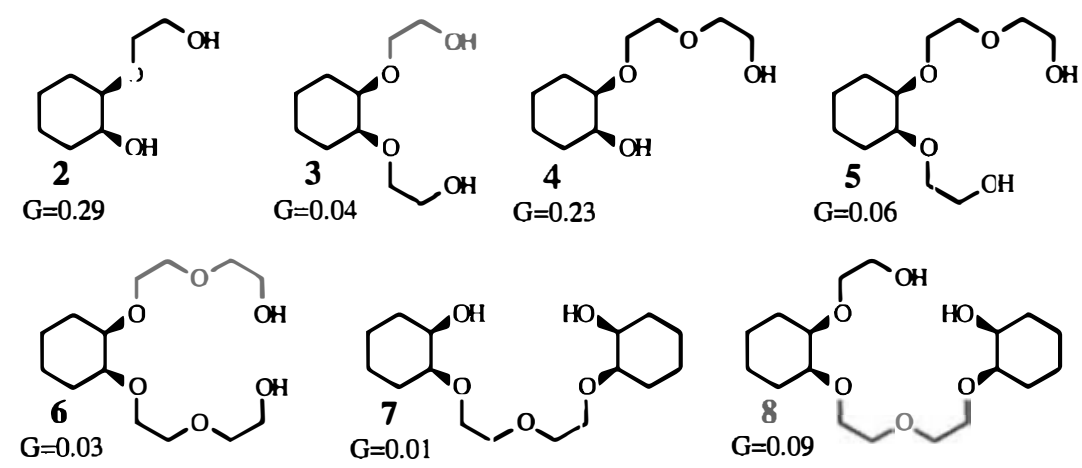

Fig. 2. Structure of the DCH18C radiolytic products and their radiochemical yields, G.

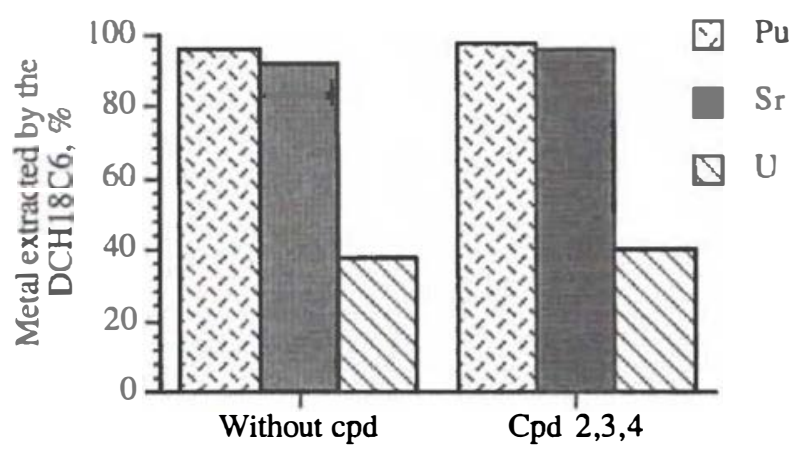

Fig. 3. Effect of the radiolytic products of DCH18C6 on $\mathrm{Pu}, \mathrm{U}$ and $\mathrm{Sr}$ extraction. [Compound 2] = [Compound 3] = [Compound 4] $=2.45 \cdot 10^{-3} \mathrm{~mol} \mathrm{~L}^{-1}$ ([radiolytic products] $=$ $\left.7.35 \cdot 10^{-3} \mathrm{~mol} \mathrm{~L}^{-1}\right)$

In order to evaluate the influence of the DCH18C6 radiolytic products on spent nuclear fuel reprocessing, experiments were performed to test whether those products modify the extraction of $\mathrm{Pu}, \mathrm{U}$ and $\mathrm{Sr}$ by DCH18C6. Compounds 2 and 4 were tested because they had the higher radiochemical yields (i.e. $\mathrm{G}=$ 0.29 and 0.23) [13]. Compound 3, which structure was representative of the symmetric structures, was tested to investigate its chelating behaviour. For an acidityadjusted second cycle solution of $4.9 \mathrm{~N}$, compounds 2 , 3 and 4 were soluble in the aqueous phase. Extraction of Pu was performed using a synthetic second cycle solution containing one or more of these radiolytic products at the concentration of $7.35 \cdot 10^{-3} \mathrm{~mol} \mathrm{~L}^{-1}$. Two tests were carried out: the first test without radiolytic product in the aqueous phase; the second one with a mixture of the three radiolytic products at the same concentration (i.e. $2.45 \cdot \mathrm{mol} \mathrm{L}^{-1}$ ) in the aqueous phase.

The loading properties of DCH18C6 are not modified by low or medium concentrations of the three radiolytic products in the aqueous medium (Fig. 3). So, considering the low radiochemical yields observed for DCH18C6 radiolysis [13], it can be concluded that the macrocycle radiolytic products do not perturb the extraction process. Indeed, it is important to note that the concentration of the DCH18C6 radiolytic products used was much higher than those expected in industrial reprocessing. To further investigate the potential of

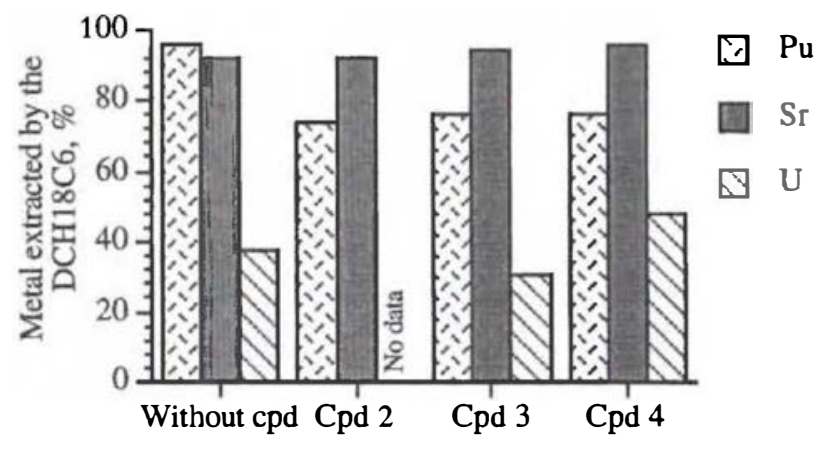

Fig. 4. Effect of the radiolytic products of DCH18C6 on Pu, U and $\mathrm{Sr}$ extraction. [Radiolytic product] $=7.35 \cdot 10^{-3} \mathrm{~mol} \mathrm{~L}^{-1}$.

DCH18C6, three tests were carried out with only one radiolytic product in the aqueous phase at a higher concentration of $7.35 \cdot 10^{-3} \mathrm{~mol} \mathrm{~L}^{-1}$ (Fig. 4).

A $20 \%$ decrease in the efficiency of Pu extraction was observed in the presence of each radiolytic product $(2,3$ and 4$)$ in the aqueous phase. Whereas, $\mathrm{Sr}$ extraction capacity by the DCH18C 6 was not modified by the presence of synthesized radiolytic products in the aqueous phase.

In order to explain the influence of the DCH18C6 radiolytic products on $\mathrm{Pu}$ extraction, a radioactive second-cycle solution was kept in contact with compound 2. Concentrations of total $\mathrm{Pu}$ and $\mathrm{Pu}$ valence states (III, IV or VI) were determined as a function of the contact time between organic and aqueous phases (Fig. 5).

$\mathrm{Pu}^{\mathrm{III}}$ was not detected in any sample of aqueous phase; DCH18C6 radiolytic products do not reduce $\mathrm{Pu}$. On the other hand, a precipitate was observed in the aqueous phase, the abundance of which was dependent on the aqueous phase/compound 2 time of contact, and decrease of free $\mathrm{Pu}$ in the aqueous phase was measured. Radiolytic product 2 precipitates $\mathrm{Pu}$ and retains it in the aqueous phase. The presence of DCH18C6 radiolytic products could block out Pu extraction in a static liquid-liquid extraction system in which the degradation products inevitably accumulate. However, they do not perturb the process in a continuous extraction system.

While DCH18C6 shows an excellent radiochemical stability, it provides high $\mathrm{Pu}$ and $\mathrm{U}$ distri- 


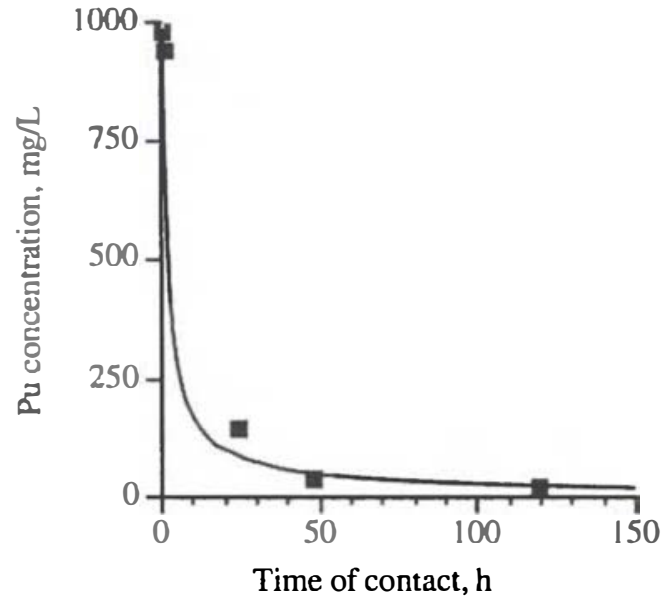

Fig. 5. Variation of free Pu concentration as a function of the time of contact between the aqueous phase and a radiolytic product 2. [2] $=9.8 \cdot 10^{-3} \mathrm{~mol}$

bution ratios in chloroform which precludes its use in a process-scale application. The development of a new liquid extraction process suitable for the spent nuclear fuel reprocessing requires an extraction system which combine an efficient, selective and radiochemically stable extractant with a diluent possessing satisfactory physical and chemical properties. Despite the use of chlorinated solvent, the high efficiency of DCH18C6 has prompted us to study a process for the recovery of $\mathrm{Sr}$ from acidic waste streams.

\section{Recovery process of $\mathrm{Sr}$}

from acidic nuclear waste streams

Among the radioelements present in traces in the waste effluents ${ }^{90} \mathrm{Sr}$, which have an half-live of nearly 30 years, is a potential hazard. Many processes have been described for the removal of this radionuclide from acidic or basic solutions. Without exception, however, these processes involve strontium concentrations from 70 [16] to 500 [8] times higher than these of the effluents we describe. The nature of the solvent, the stereochemical configuration of the DCH18C6 isomer and the extractant concentration were studied in view of the removal of strontium traces in the presence of an excess of sodium. The best results were obtained using chloroform as solvent and a solution of DCH18C6 at the concentration of $0.022 \mathrm{M}$.

The potential of the DUOLITE ARC-9652, an organic ion exchanger, for the concentration of $\mathrm{Sr}$ was then examined. The results obtained have shown that the removal of traces of strontium from $0.9 \mathrm{M}$ nitric solution containing an excess of sodium can be achieved using this resin. Thus, properties of selective extraction of DCH18C6 and concentration of the DUOLITE ARC-9652 were combined in a continuous process of strontium extraction, stripping and concentration.

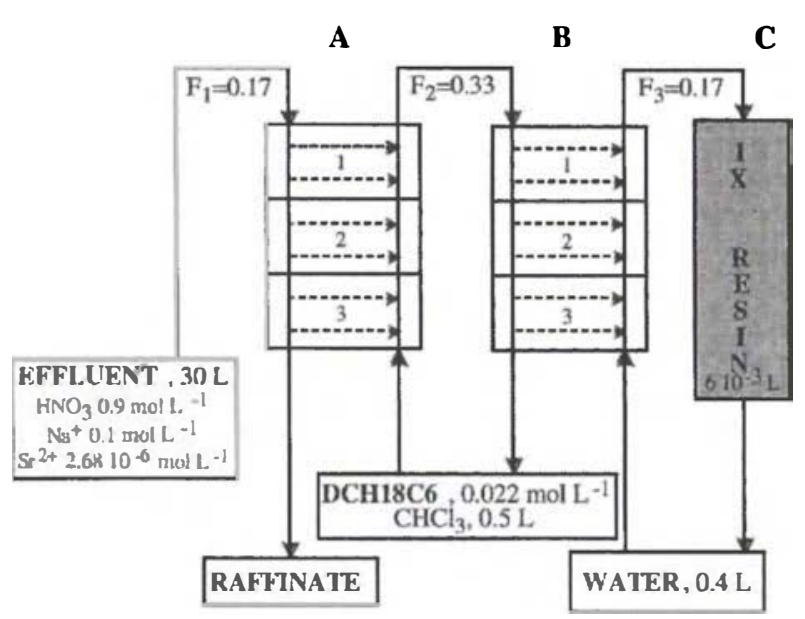

A Extraction B Stripping CConcentration

Fig. 6. Pilot installation for strontium extraction and recovery. $F_{1}=$ Effluent flow rate $\left(\mathrm{L} \mathrm{h}^{-1}\right), \mathbf{F}_{2}=$ Organic phase flow rate $\left(\mathrm{L} \mathrm{h}^{-1}\right), \mathrm{F}_{3}=\mathrm{Sr}$ stripping flow rate $\left(\mathrm{Lh}^{-1}\right)$.

The pilot installation shown in Figure 6 was used to selectively remove ${ }^{90} \mathrm{Sr}$ from acidic solution in the presence of $30 \cdot 10^{3}$ molar excess of sodium. The equipment for doing the process study consists of an extraction reactor and a stripping reactor (mixersettlers). The number of theoretical stages of liquidliquid extraction was calculated according to the "Kremser formula" [17]. A pH-adjusted synthetic-effluent $\left(\mathrm{pH}=0.46\right.$ for $0.9 \mathrm{M} \mathrm{HNO}_{3}$ ) with a flow rate of $0.17 \mathrm{~L} \mathrm{~h}^{-1}$ was added at the first stage to the solvent introduced at the third stage with a flow rate of $0.33 \mathrm{~L} \mathrm{~h}^{-1}$. In three stages $99,6 \%$ of strontium was extracted with a DCH18C6 concentration of $0.022 \mathrm{M}$. Sr decontamination factors ( $\mathrm{Sr}$ concentration in effluent/ $\mathrm{Sr}$ concentration in raffinate) of 250 were measured.

The strontium was then stripped in three stages, introducing at the third stage, water at a flow rate of $0.17 \mathrm{~L} \mathrm{~h}^{-1}$. In those conditions, more than $90 \%$ of strontium was stripped.

Then, the strontium was continuously concentrated onto $6 \cdot 10^{-3} \mathrm{~L}$ of Duolite ARC-9652 ion-exchange re$\sin$. So, traces of strontium contained in $30 \mathrm{~L}$ of effluent were concentrated on to $6 \cdot 10^{-3} \mathrm{~L}$ of resin leading to a calculated extraction factor of 5000; strontium was then readily eluted with $5 \mathrm{M} \mathrm{HNO}_{3}$.

\section{Conclusions}

The DCH18C6, and specifically the cis-syn-cis isomer of this macrocycle, possesses a high stability toward radiolysis. The cis-syn-cis DCH18C6 radiolytic products would bring few effect on continuous extraction system. Moreover, we demonstrate here that a continuous process based on liquid-liquid extraction $\left(\mathrm{DCH} 18 \mathrm{C} 6-\mathrm{CHCl}_{3}\right)$ and solid-liquid concentration (Duolite ARC-9652) provides an effective method for extraction and recovery of strontium traces in the presence of an excess of sodium from nitric acid 
media. Indeed, strontium contained in 30-L sample of radioactive effluent is selectively extracted by the DCH18C6, in the presence of $30 \cdot 10^{3}$ molar excess of sodium, and then concentrated onto $6 \mathrm{~mL}$ of an ionexchange resin. The overall process therefore reduces the volume of material containing the $\mathrm{Sr}$ by a factor of 5000 and fixes this soluble species onto a small volume of organic material.

\section{Acknowlegment}

The authors are grateful to G. Le Buzit for helpful discussions.

\section{References}

1. Rice, N. M., Irving, H. M. N., Leonard, M. A.: Pure and Appl. Chem. 65(11), 2373 (1993).

2. Okahara, M., Nakatsuji, Y.: Crown Ethers and Analogous Compounds (M. Hiraoka, Ed.) Elsevier 1992.

3. Khopkar, S. M., Gandhi, M. N.: Solvent Extraction Separations with Crown Ethers and Cryptands, J. Sci. Ind. Res. 55, 139 (1996).

4. Favre-Réguillon, A., Dumont, N., Dunjic, B., Lemaire, M.: Synthesis and Evaluation of New Polyurethane Based Material for Ion Separation, Tetrahedron Lett. 36(36), 6439 (1995).

5. Guyon, V., Moutarde, T., Draye, M., Chomel, R., Foos, J., Guy, A., Lemaire, M.: Synthesis and Utilization of New Extractants for Nuclear Hydrometallurgy, Sep. Sci. Technol. 30, 1961 (1995).

6. Lemaire, M., Guy, A., Chomel, R., Foos, J.: Dicyclohexano18-crown-6 Ether: A New Selective Extractant for Nuclear Fuel Reprocessing, J. Chem. Soc., Chem. Commun. 1152 (1991).

7. Dozol, M., Casas, J., Garcia, I., Sastre, M.: Application of Crown-Ethers to Caesium and Strontium Removal from Marcoule Reprocessing Concentrate. In: New Separation
Chemistry Techniques for Radioactive Waste and other Specific Applications (L. Cecille, M. Casarci, L. Pietrelli, Eds.) Elsevier 1991, p. 173.

8. Horwitz, E. P., Dietz, M. L., Fisher, D. E.: SREX: A New Process for the Extraction and Recovery of Strontium from Acidic Nuclear Waste Streams, Solvent Extr. Ion Exch. 9(1), 1 (1991).

9. Samanta, S. K., Ramaswamy, M., Misra, B. M.: Synthesis and Characterization of some Phenolic Resins for the Selective Removal of Radiostrontium, Radiochim. Acta 57, 201 (1992).

10. Schulz, W. W., Bray, L. A.: Solvent Extraction Recovery of Byproduct ${ }^{137} \mathrm{Cs}$ and ${ }^{90} \mathrm{Sr}$ from $\mathrm{HNO}_{3}$ Solutions - a Technology Review and Assessment, Sep. Sci. Technol. 22, 191 (1987).

11. Guyon, V., Drognat Landré, P., Guy, A., Foos, J., Lemaire, M.: Easy Separation of the Cis-syn-cis and Cis-anti-cis Isomers of Dicyclohexyl-18-crown-6, Chem. Letters 723 (1992).

12. Draye, M., Favre-Réguillon, A., Chomel, R., Faure, R., Guy, A., Foos, J., Lemaire, M.: Radiochemical Stability of the Dicyclohexano-18-crown-6 Ether (DCH18C6): Synthesis and Tests in Radioactive Medium of the DCH18C6 Radiolytic Products, Bull. Soc. Chim. Fr. 133, 183 (1996).

13. Draye, M., Chomel, R., Doutreluingne, P., Guy, A., Foos, J., Lemaire, M.: Radiolytic Products Study of Dicyclohexano-18-crown-6, a Selective Extractant for Nuclear Fuel Reprocessing, J. Radioanal. Nucl. Chem. Lett. 175(1), 55 (1993).

14. Cox, B. G., Schneider, H.: Coordination and Transport Properties of Macrocyclic Compounds In Solution, Elsevier 1992, p. 87.

15. Schulz, W. W., Navratil, J. D., Talbot, A. E.: Technology of Tributyl Phosphate, CRC Press Inc., Boca Raton, Fla 1984, vol. 1, p. 238.

16. Wood, D. J., Tranter, T. J., Todd, T. A.: Effect of the Interference of Alkali and Alkaline Earth Metal Ions on the Extraction of ${ }^{90} \mathrm{Sr}$ from Acidic Nuclear Waste Solutions by 18 crown-6 Derivatives, Solvent Extr. Ion Exch. 13(5), 829 (1995).

17. Treybal, R.: Solvent extraction. In: Chemical Engineer's Handbook, (Robert H. Perry, Cecil H. Chilton, Eds.), McGraw-Hill 1973, chap. 15-19. 